\title{
Thermoregulated expression of virulence genes in enteropathogenic Escherichia coli
}

\author{
Tatiana Umanski, Ilan Rosenshine and Devorah Friedberg
}

Department of Molecular Genetics and Biotechnology, The Hebrew University, Faculty of Medicine, POB 12272, Jerusalem 91120, Israel

\author{
Author for correspondence: Ilan Rosenshine. Tel: +972 2 6758754. Fax: +972 26784010. \\ e-mail: ilanro@cc.huji.ac.il
}

\begin{abstract}
Enteropathogenic Escherichia coli (EPEC) causes severe diarrhoea in young children. The locus of enterocyte effacement (LEE) pathogenicity island comprises a cluster of operons encoding a type III secretion system and related proteins that are associated with EPEC virulence. The LEE1 operon encodes Ler that positively regulates the LEE2, LEE3, LEE4, LEE5 and espG transcriptional units. The LEE operons are repressed at $27^{\circ} \mathrm{C}$ and expressed at $37^{\circ} \mathrm{C}$. This paper describes a regulatory cascade of the thermoregulation of LEE operons. LEE1 including ler is repressed by $\mathrm{H}-\mathrm{NS}$ at $27^{\circ} \mathrm{C}$ but not at $37^{\circ} \mathrm{C}$. In contrast, the expression of the LEE2, LEE3, LEE4, LEE5 and espG transcriptional units is repressed by $\mathrm{H}-\mathrm{NS}$ at both $27^{\circ} \mathrm{C}$ and $37^{\circ} \mathrm{C}$. Upon shifting the culture temperature from $27^{\circ} \mathrm{C}$ to $37^{\circ} \mathrm{C}$, Ler is synthesized and in turn activates the expression of LEE2, LEE3, LEE4 and espG by releasing the H-NS mediated repression. In the case of LEE5, Ler acts both by alleviating the H-NS mediated repression and by an additional mechanism, as yet to be defined.
\end{abstract}

Keywords: EPEC, LEE, H-NS, Ler, thermoregulation

\section{INTRODUCTION}

Enteropathogenic Escherichia coli (EPEC) causes severe diarrhoea in young children. The disease is associated with formation of attaching and effacing (AE) lesions in infected epithelial cells. Formation of AE lesions is involved with localized degeneration of the brush border microvilli and assembly of highly organized pedestallike actin structures in the epithelial cells beneath intimately attached bacteria (Frankel et al., 1998). EPEC possesses a unique $35.6 \mathrm{kbp}$ pathogenicity island, termed the locus of enterocyte effacement (LEE), that contains genes needed to elicit formation of AE lesions (McDaniel \& Kaper, 1997). The LEE consists of 41 ORFs, organized in five major operons, LEE1 to LEE5, and several additional transcriptional units (Elliott et al., 1999, 1998; McDaniel \& Kaper, 1997). These genes encode effector proteins and a type III secretion system, which functions as a molecular syringe to translocate effector proteins from the bacterial cytoplasm directly into the cytoplasm of host cells (Knutton et al., 1998; Wolff et al., 1998). The type III secretion system is essential for

Abbreviations: EPEC, enteropathogenic Escherichia coli; GFP, green fluorescent protein; LEE, locus of enterocyte effacement; H-NS, histonelike nucleoid-structuring protein; Ler, LEE-encoded regulator; IHF, integration host factor; Tir, translocated intimin receptor.
AE lesion formation, for colonization of the host and for EPEC virulence.

We previously showed that expression of the LEEencoded type III secretion system is thermoregulated, being repressed at $27^{\circ}$, and expressed at $37^{\circ} \mathrm{C}$ (Rosenshine et al., 1996). Thermoregulated expression of virulence genes was reported also in enteroinvasive $E$. coli (Forsman et al., 1992; Jordi et al., 1992) and Shigella (Maurelli \& Sansonetti, 1988). In some of these cases HNS (histone-like nucleoid-structuring protein) plays a key role in the repression at the non-permissive temperature. H-NS is a nucleoid-associated protein, frequently involved in the response of enterobacteria to environmental stimuli. In most cases it mediates negative regulation and counteracts a positive regulator (Atlung \& Ingmer, 1997). In E. coli K-12 H-NS is involved, directly or indirectly, in the regulation of about $5 \%$ of the genes (Hommais et al., 2001).

Expression of LEE2, LEE3, LEE4, LEE5, espG and orf19 is activated by Ler (LEE-encoded regulator), a distant homologue of H-NS, encoded by the LEE1 operon (Friedberg et al., 1999; Mellies et al., 1999; SanchezSanMartin et al., 2001; Sperandio et al., 2000). Therefore, the decision whether or not to activate expression of LEE1 is critical for the initiation of a regulatory cascade leading to expression of other LEE operons. 
Table 1. Bacterial strains and plasmids

\begin{tabular}{|c|c|c|}
\hline Strain or plasmid & Relevant genotype and characteristics & Reference or source \\
\hline \multicolumn{3}{|l|}{ E. coli strains } \\
\hline EPEC 2348/69 & EPEC wild-type, $\mathrm{Sm}^{\mathrm{r}}$ & J. Kaper, Uni. Maryland \\
\hline SY327 $\lambda$ pir & Used for propagation of pCVD442 & Donnenberg \& Kaper (1991) \\
\hline SM10 ipir & thi1 thr leu tonA lacY recA supE (RP4-2 $\mathrm{Km}^{\mathrm{r}}$ tet:: $\left.\mathrm{Mu}\right)$ & Donnenberg \& Kaper (1991) \\
\hline $\mathrm{DH} 5 \alpha$ & supE44 $\Delta$ lacU169 ( $\phi 80$ lacZLM15) hsdR17 recA1 endA1 gyrA96 thi-1 relA1 & BRL \\
\hline E. coli BL21 & $F^{-}$gal met $r^{-} m^{-}$hsdS $\lambda_{1 \mathrm{ys}}$ placUV5-T7-gene 1placI ${ }^{q}$ & Studier \& Moffatt (1986) \\
\hline DF2 & $\mathrm{E} 2348 / 69$ ler:: kan & Friedberg et al. (1999) \\
\hline DF3 & $\mathrm{E} 2348 / 69$ hns::kan & This study \\
\hline TU1 & E2348/69 ler::kan hns::cat & This study \\
\hline \multicolumn{3}{|l|}{ Plasmids } \\
\hline pCVD442 & A suicide vector containing the $s a c B$ gene & Donnenberg \& Kaper (1991) \\
\hline pKD46 & Expresses Lambda Red recombinase & Datsenko \& Wanner (2000) \\
\hline pKD3 & A template plasmid carrying the cat gene & Datsenko \& Wanner (2000) \\
\hline pBS & Cloning vector & Stratagene \\
\hline pIR1 & pKK177-3 derivative containing $g f p$ mut 3 & Friedberg et al. (1999) \\
\hline pUC4K & Contains $1 \cdot 2 \mathrm{~kb}$ kan cassette & Pharmacia \\
\hline pPD3 & A vector expressing T7-hns & Dersch et al. (1994) \\
\hline pDF6 & pBS containing EPEC hns and flanking sequences & This study \\
\hline pDF7 & pBS containing $h n s:$ kan & This study \\
\hline pDF8 & pCVD442 containing hns::kan & This study \\
\hline pTU15 & pBS containing $h n s:: c a t$ & This study \\
\hline pTU1 & pIR1 containing $L E E 1:: g f p$ & This study \\
\hline pYF4 & pIR1 containing $L E E 2:: g f p$ & Friedberg et al. (1999) \\
\hline pYF5 & pIR1 containing $L E E 3:: g f p$ & Friedberg et al. (1999) \\
\hline pTU9 & pIR1 containing $\operatorname{esp} G:: g f p$ & This study \\
\hline pTU10 & pIR1 containing $L E E 4:: g f p$ & This study \\
\hline pTU11 & pIR1 containing $L E E 5:: g f p$ & This study \\
\hline pTU14 & pACYC184 derivative containing $l a c I^{a}$ and Ptac-ler & This study \\
\hline
\end{tabular}

LEE1 expression is dependent on activation by Integration Host Factor (IHF) (Friedberg et al., 1999). Additional factors, including Fis, Per and quorum sensing, are involved in modulation of LEE1 gene expression (Goldberg et al., 2001; Kanamaru et al., 2000; Mellies et al., 1999; Sperandio et al., 1999). Recently it was reported that in the K-12 background, $\mathrm{H}-\mathrm{NS}$ acts as a negative regulator of LEE2, LEE3 and orf19 (Bustamante et al., 2001; Sanchez-SanMartin et al., 2001). It was hypothesized that Ler activates gene expression by negating the H-NS-mediated repression (Bustamante et al., 2001; Sanchez-SanMartin et al., 2001). In conclusion, the LEE operons are subject to regulation by multiple factors; some, like IHF, H-NS and Fis are global regulators expressed by K-12 laboratory strains, and others like Ler, Per and perhaps other regulators are specific to EPEC.

The involvement of any of the above factors, including $\mathrm{H}-\mathrm{NS}$ and Ler, in thermoregulation is not clear. In this communication we describe the role of H-NS in thermoregulated expression of the LEE operons. We report, for the first time, the formation of an EPEC hns mutant and an EPEC double mutant of hns and ler. We used these mutants to analyse the role of hns and ler in the thermoregulated expression of LEE genes. The genetic analysis was supported by in vitro biochemical analyses using a purified H-NS protein. We show that H-NS is involved in two levels of regulation of the LEE genes. First, it represses the expression of LEE1 (including ler) at $27^{\circ} \mathrm{C}$ but not at $37^{\circ} \mathrm{C}$, leading to thermoregulated expression of all other Ler-regulated LEE operons. In addition, H-NS represses expression of the LEE2, LEE3, LEE4, LEE5 and espG operons both at $27^{\circ} \mathrm{C}$ and at $37^{\circ} \mathrm{C}$. Upon shifting the culture temperature from $27^{\circ} \mathrm{C}$ to $37^{\circ} \mathrm{C}$, the expressed Ler activates the expression of LEE2, LEE3, LEE4 and espG by releasing the H-NSmediated repression. In the case of LEE5, Ler acts both by antagonizing the H-NS-mediated repression and by an additional mechanism, as yet to be defined.

\section{METHODS}

Bacterial strains, culture conditions and oligonucleotide primers. EPEC strains were grown in LB overnight at $27^{\circ} \mathrm{C}$, diluted 1:50 in DMEM and grown to $\mathrm{OD}_{600} 0 \cdot 3-0.35$ at $37^{\circ} \mathrm{C}$ or $27^{\circ} \mathrm{C}$ as indicated. The $\mathrm{pH}$ of the DMEM was adjusted by adding HEPES buffer (Sigma) at $\mathrm{pH} 7 \cdot 4$ to a final concentration of $20 \mathrm{mM}$. When needed IPTG $(1 \mathrm{mM})$ was added $1 \mathrm{~h}$ before cultures were harvested. When needed we used $100 \mu \mathrm{g}$ ampicillin (Amp) $\mathrm{ml}^{-1}, 40 \mu \mathrm{g}$ kanamycin (Kan) $\mathrm{ml}^{-1}, 25 \mu \mathrm{g}$ chloramphenicol $(\mathrm{Cm}) \mathrm{ml}^{-1}$ and $100 \mu \mathrm{g}$ streptomycin (Str) 
Table 2. Oligonucleotides used in this study

\begin{tabular}{|c|c|c|c|}
\hline Name & Sequence $\left(5^{\prime}-3^{\prime}\right)$ & $\begin{array}{c}\text { Map position } 5^{\prime} \\
\text { alignment }\end{array}$ & Accession no. \\
\hline \multicolumn{4}{|c|}{ LEE 1 and $\operatorname{esp} G$} \\
\hline $24 \mathrm{R}$ & GCTCTAGACCTTCTTCATTGCGGTAG & 4332 & AF022236 (LEE) \\
\hline $5 \mathrm{R}$ & GCTCTAGATTCTCTGTTTTCTAATGTG & 3924 & \\
\hline $9 \mathrm{~F}$ & GGAATTCGTTTATGCAATGAGATCTATC & 3740 & \\
\hline $27 \mathrm{R}$ & GCTCTAGAGAGAGCGTCAGCGAAACG & 4183 & \\
\hline $14 \mathrm{~F}$ & GCTCTAGAGGCAACAAGTATCATATAGC & 2804 & \\
\hline $8 \mathrm{R}$ & CGGGATCCGCATGCTTTAATATTTTAAGC & 4076 & \\
\hline $26 \mathrm{~F}$ & CGGGATCCAAGCGGATCTGTTTGAGC & 2240 & \\
\hline \multicolumn{4}{|c|}{$L E E 2$ and $L E E 3$} \\
\hline $30 \mathrm{~F}$ & GCTCTAGACTGCGTACGCTCAGGAGC & 14654 & \\
\hline $31 \mathrm{R}$ & GCTCTAGACTGCGTACGCTCAGGAGC & 15058 & \\
\hline \multicolumn{4}{|l|}{ tir } \\
\hline $22 \mathrm{~F} 1$ & GAGTGGATCCCATTACAC & 22045 & \\
\hline 22R1 & GCTCTGAGAGAAGCGTCTTCTGCTC & 23814 & \\
\hline \multicolumn{4}{|c|}{ LEE4 and upstream } \\
\hline $32 \mathrm{R}$ & GCTCTAGACAGATCGCTTTGTGCC & 30539 & \\
\hline $39 \mathrm{~F}$ & CGGGATCCATGCCATACCAGAGTG & 27885 & \\
\hline \multicolumn{4}{|l|}{ hns } \\
\hline hnsF4 & CGCAAGCTTCAGTATGCACAGAAGTGG & 10273 & D90759 \\
\hline hnsR4 & CGGGATCCGTTGCGCCGTCTAATCTC & 9071 & \\
\hline \multicolumn{4}{|l|}{ CIII } \\
\hline 2703 & GCGGAATTCGAATTTAGTCTGGATAGC & & \\
\hline 2902 & GCCGGATCCATGCAATATGCCATTGCAGG & & \\
\hline \multicolumn{4}{|l|}{ cat } \\
\hline cm-pKD3-F & AACTGCAGGTGTAGGCTGGAGCTGCTTC & & \\
\hline cm-pKD3-R & AACTGCAGCATATGAATATCCTCCTTAG & & \\
\hline
\end{tabular}
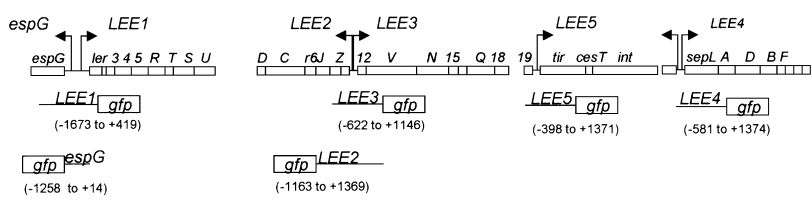

$(-1258$ to +14$)$

Fig. 1. Schematic presentation of LEE operon-gfp transcriptional fusions. An overview (not to scale) of LEE DNA indicating LEE genes (white boxes) and LEE transcriptional units including LEE1, LEE2, LEE3, LEE4, LEE5 and espG (Elliott et al., $1999,1998)$ is shown. The arrows indicate the direction of transcription. The corresponding $g f p$ fusions analysed in this study are shown and their sequence position relative to the corresponding transcriptional start sites are indicated. In the case of espG where the transcriptional start site is unknown, the indicated positions are relative to the putative translational start site.

$\mathrm{ml}^{-1}$. Bacterial strains and plasmids used in this study are listed in Table 1; the oligonucleotides are listed in Table 2.

Construction of $\boldsymbol{g} \boldsymbol{f p}$ transcriptional fusions. DNA fragments were amplified by PCR using specific oligonucleotides (Table 2), digested by BamHI and XbaI and cloned into the BamHI and $X b a I$ sites of $\mathrm{pIR} 1$ to form transcriptional fusions with the $g f p-m u t 3$ gene encoding green fluorescent protein (Cormack et al., 1996) as previously described (Friedberg et al., 1999). Plasmids containing the $g f p$ fusions are listed in Table 1 . The amplified fragments including the regulatory regions of the corresponding LEE operons are presented in Fig. 1.

Measurements of gene expression by flow cytometry. Gene expression of bacterial strains containing $g f p$ fusions was monitored by flow cytometry as previously described (Friedberg et al., 1999). Cultures grown as indicated above (see Bacterial strains) were centrifuged and suspended in filtered PBS to $\mathrm{OD}_{600} 0 \cdot 3$. Fluorescence intensity of $10^{4}$ bacterial-sized particles was acquired and the mean values were presented. Fluorescence measurements were performed with a FACScan cytometer (Becton Dickinson). Data analysis was performed with the program CELLQuest. Experiments were repeated at least three times and the standard error was calculated.

Protein extraction and immunoblot analysis. Bacterial cultures grown as indicated above (see Bacterial strains) were centrifuged and extracted by boiling for $7 \mathrm{~min}$ in lysis buffer ( $1 \% \mathrm{SDS}$ and $50 \mathrm{mM}$ Tris $/ \mathrm{HCl} \mathrm{pH} \mathrm{7.5),} 2$ min centrifugation at $14000 \mathrm{~g}$ and collecting the supernatant. Protein concentrations of the samples were adjusted and samples were subjected to SDS-PAGE, transferred to nitrocellulose membranes and treated with antibodies as described (Wolff et al., 1998).

Construction of EPEC mutants. To construct an EPEC hns mutant, a 1380 bp DNA fragment containing EPEC hns gene and flanking regions was amplified by PCR using EPEC DNA 
and primers hnsF4 and hnsR4 (Table 2). A BamHI/HindIII digest of the amplified DNA fragment was cloned into the BamHI/HindIII sites of the pBS plasmid to form pBS-hns (pDF6). A $1.2 \mathrm{~kb}$ DNA fragment containing the kan gene cassette was purified as a PstI fragment from pUC4K (Pharmacia), cloned into the Pst I site of the hns gene in pDF6 to form pDF7 (pBS-hns::kan). A BamHI-XhoI DNA fragment containing the $h n s:$ : kan DNA was purified from pDF7 treated with Klenow fragment (MBI Fermentas) and cloned into the SmaI site of pCVD442 to form pDF8 (pCVD-hns::kan), in SY327 $\lambda$ pir strain. pDF8 was then electroporated into E. coli SM10 $\lambda$ pir. EPEC insertionally inactivated hns mutant (designated DF3) was created by allelic exchange of wild-type hns with hns: kan carried by pDF8, using the sucrose selection method (Donnenberg \& Kaper, 1991).

We adopted and modified the one-step inactivation method of chromosomal gene disruption that makes use of the Lambda Red recombinase in E. coli K-12 (Datsenko \& Wanner, 2000), to operate in EPEC. This system, that enables recombination of linear DNA fragments in the E. coli genome (Datsenko \& Wanner, 2000), was used to construct an EPEC ler::kan hns:: cat double mutant. A DNA fragment containing the cat gene was amplified from plasmid pKD3 (Datsenko \& Wanner, 2000), using primers cm-pKD3-F and cm-pKD3-R. The cat fragment was cloned into the PstI site of pDF6 to construct pTU15 (pBS-hns::cat). EPEC ler::kan (Friedberg et al., 1999) was electroporated with plasmid pKD46 containing the Lambda Red recombinase (Datsenko \& Wanner, 2000). This strain was subsequently electroporated with a linear DNA fragment containing hns::cat, that was amplified with primers hnsF4 and hnsR4, using pTU15 DNA as a template. $\mathrm{Cm}^{\mathrm{r}}$ clones were selected at $37^{\circ} \mathrm{C}$, streaked twice and $\mathrm{cm}^{\mathrm{r}}$ amp clones that had lost pKD46 were selected. PCR analysis confirmed replacement of the wild-type $h n s$ gene by $h n s:$ :cat and the formation of EPEC ler::kan hns::cat double mutant.

H-NS purification. Native, untagged $\mathrm{H}-\mathrm{NS}$ was purified to homogeneity from an H-NS-producing clone of E. coli BL21/pPD3 as described by Dersch et al. (1993). The published procedure was scaled down to 11 bacterial culture and the purified H-NS was concentrated to $3 \mathrm{mg} \mathrm{ml}^{-1}$ using Centricon YM-10 (Amicon).

DNA band shift assay with H-NS. Three DNA fragments were used: a 186 bp DNA fragment corresponding to the sequence from position -173 to +11 relative to the LEE1 transcriptional start point (LEE1 fragment), amplified with primers 9F and 5R; a 395 bp PCR fragment corresponding to sequence from position +117 to -288 nucleotides relative to LEE2 transcriptional start point (LEE2-LEE3 fragment), amplified with primers $30 \mathrm{~F}$ and $31 \mathrm{R}$; and a DNA fragment $171 \mathrm{bp}$ in size containing the $\lambda C I I I$ coding region, amplified with primers 2703 and 2902. The LEE fragments and the CIII fragment were digested by $\mathrm{XbaI}$ and EcoRI respectively and end-labelled by filling in using Klenow fragment of DNA polymerase I (MBI Fermentas) and $\left[\alpha^{32} \mathrm{P}\right] \mathrm{dCTP}\left(3000 \mathrm{Ci} \mathrm{mmol}{ }^{-1}\right.$; Amersham). Binding of H-NS to the end-labelled DNA (3-6 fmol) was performed at $25^{\circ} \mathrm{C}$ for $30 \mathrm{~min}$, in $10 \mu \mathrm{l}$ binding buffer containing: $50 \mathrm{mM}$ Tris/ $\mathrm{HCl}$ (pH 7.4), $70 \mathrm{mM} \mathrm{KCl,} 1 \mathrm{mM}$ EDTA, $10 \mathrm{mM} \beta$-mercaptoethanol, $100 \mu \mathrm{g}$ bovine serum albumin $\mathrm{ml}^{-1}, 6 \%$ glycerol and $100 \mathrm{ng}$ poly(dI-dC) (Boehringer). At the end of the incubation period the samples were loaded on $4.5 \%$ polyacrylamide gel (acrylamide to bisacrylamide, $37 \cdot 5: 1 \mathrm{w} / \mathrm{w})$ in $0.5 \times \mathrm{TBE}$ buffer and electrophoresis was carried out at room temperature. The dried gels were exposed for autoradiography and the results were quantified using a phosphorimager (Fuji) as described.

\section{RESULTS}

Expression of LEE1, LEE2, LEE3, LEE4, LEE5 and espG is negatively regulated by $\mathrm{H}-\mathrm{NS}$ in a temperaturedependent manner

We constructed an hns mutant of EPEC (bns::kan) (see Methods) and tested the role of H-NS in the expression of all major LEE transcriptional units. We compared three EPEC strains: wild-type, hns: kan mutant and the hns mutant complemented by a plasmid encoding H-NS (pDF6). These strains were grown in DMEM at $27^{\circ} \mathrm{C}$ or $37^{\circ} \mathrm{C}$ to $\mathrm{OD}_{600} 0 \cdot 3-0.35$ and tested for production of LEE encoded proteins using Western analysis with antibodies raised against Ler (LEE1 encoded), intimin and Tir (translocated intimin receptor; LEE5 encoded) and EspA, EspB and EspF (LEE4 encoded) (Fig. 2). At $27^{\circ} \mathrm{C}$, production of these proteins was repressed in the presence of H-NS and derepressed in the absence of $\mathrm{H}$ NS. At $37^{\circ} \mathrm{C}$ all the strains expressed these proteins but the expression was somewhat more efficient in the hns mutant strain (Fig. 2).

We further tested the role of H-NS in LEE regulation by an additional, independent approach. EPEC wild-type and EPEC hns::kan mutant were transformed with plasmids containing transcriptional fusions of the $g f p$ reporter gene with DNA fragments containing the regulatory sequences of the LEE1, LEE2, LEE3, LEE4, $L E E 5$ and $\operatorname{esp} G$ transcriptional units (Fig. 1). The strains were grown at $37^{\circ} \mathrm{C}$ or $27^{\circ} \mathrm{C}$ and the level of GFP was

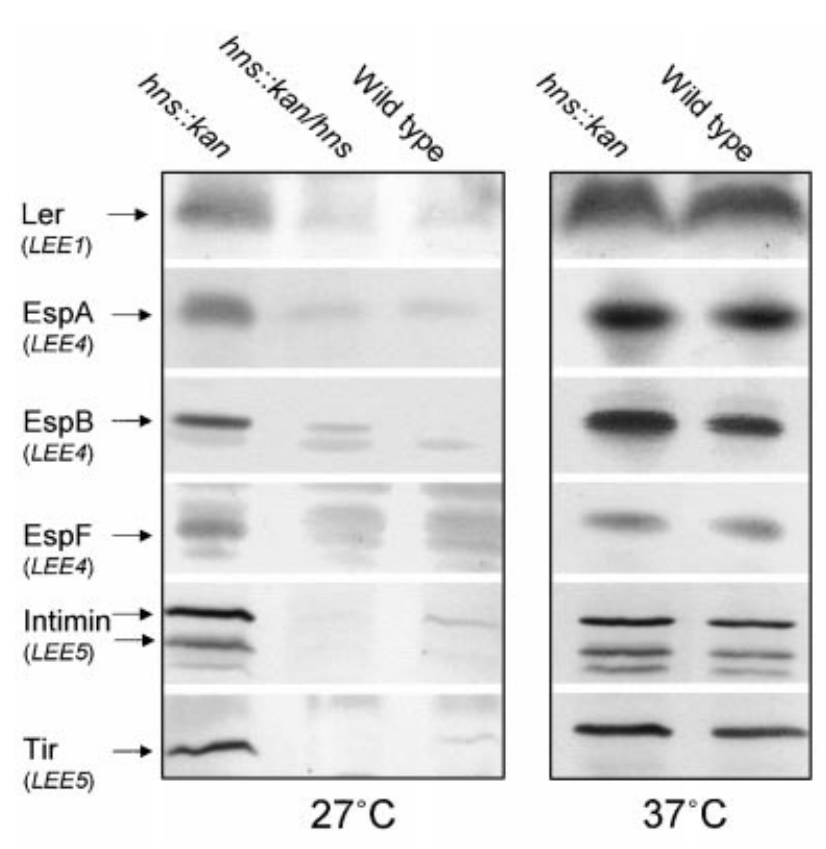

Fig. 2. Expression of LEE genes is derepressed in EPEC hns null mutant grown at $27^{\circ} \mathrm{C}$. Proteins were extracted from hns::kan, $h n s:: k a n / p B S-h n s$ and EPEC wild-type grown in DMEM at $27^{\circ} \mathrm{C}$ or $37^{\circ} \mathrm{C}$. The extracted proteins were applied to SDS-PAGE followed by immunoblot analysis, using anti-Ler, anti-EspA, anti-EspB, anti-EspF, anti-Tir and anti-Intimin antibodies. 
Table 3. Thermoregulation of LEE genes

EPEC hns::kan mutant and EPEC wild-type containing the indicated $g f p$ transcriptional fusions were grown in DMEM at $27^{\circ} \mathrm{C}$ or $37^{\circ} \mathrm{C}$ and analysed for $g f p$ expression using flow cytometry. Each of the fluorescence values is the mean value of three experiments, and the standard error is shown in parentheses. The level of derepression is the ratio of the fluorescence values of $h n s:$ kan to wildtype.

\begin{tabular}{|c|c|c|c|c|c|c|}
\hline \multirow[t]{2}{*}{$L E E:: g f p$} & \multicolumn{3}{|c|}{$27^{\circ} \mathrm{C}$} & \multicolumn{3}{|c|}{$37^{\circ} \mathrm{C}$} \\
\hline & hns::kan & Wild-type & $\begin{array}{l}\text { Derepression } \\
\text { level }\end{array}$ & hns::kan & Wild-type & $\begin{array}{c}\text { Derepression } \\
\text { level }\end{array}$ \\
\hline LEE1 & $396(24)$ & $23(1 \cdot 7)$ & $17 \cdot 2$ & $261(14)$ & $126(8)$ & $2 \cdot 1$ \\
\hline $\operatorname{esp} G$ & $156(22)$ & $6(0 \cdot 14)$ & $26 \cdot 0$ & $132(10)$ & $41(3)$ & $3 \cdot 2$ \\
\hline LEE2 & $338(22)$ & $6(0 \cdot 43)$ & $56 \cdot 3$ & $413(21)$ & $176(6 \cdot 5)$ & $2 \cdot 3$ \\
\hline LEE3 & $239(21)$ & $9(0 \cdot 15)$ & $26 \cdot 6$ & $114(10)$ & $89(7)$ & $1 \cdot 3$ \\
\hline LEE4 & $641(30)$ & $39(3)$ & $16 \cdot 4$ & 704 (49) & $413(32)$ & $1 \cdot 7$ \\
\hline LEE5 & $108(5)$ & $9(0 \cdot 5)$ & $12 \cdot 0$ & $122(3)$ & $86(6)$ & $1 \cdot 4$ \\
\hline Ptac & $130(4)$ & $122(3 \cdot 6)$ & $1 \cdot 1$ & $138(7)$ & $136(9 \cdot 5)$ & $1 \cdot 0$ \\
\hline
\end{tabular}

determined (Table 3). Expression of $g f p$ by cells grown at $37^{\circ} \mathrm{C}$ was similar in EPEC wild-type and $h n s$ mutant strains, with somewhat higher GFP levels in the hns mutant. In contrast, $g f p$ expression of wild-type EPEC grown at $27^{\circ} \mathrm{C}$ was very low, while the hns::kan mutant grown at $27^{\circ} \mathrm{C}$ expressed $g f p$ efficiently to levels somewhat higher than wild-type levels at $37^{\circ} \mathrm{C}$ (Table 3 ). We observed that in the hns mutant background the plasmid copy number is about twofold higher compared with the wild-type level. This could increase the GFP level in the hns mutant by twofold. The results with the $g f p$ transcriptional fusions are in agreement with the Western analysis shown in Fig. 2. Taken together these results indicate that expression of $L E E 1, L E E 2, L E E 3$, $L E E 4, L E E 5$ and $\operatorname{esp} G$ is negatively regulated by $\mathrm{H}-\mathrm{NS}$ at the non-permissive temperature of $27^{\circ} \mathrm{C}$.

\section{Ler expressed in trans rescues the expression of Ler- activated LEE genes at $27^{\circ} \mathrm{C}$}

The above results indicate that the LEE1-encoded ler is derepressed at $27^{\circ} \mathrm{C}$ in EPEC hns: kan mutant. Therefore we tested whether the expression of ler is sufficient to activate expression of the Ler-activated LEE2, LEE3, LEE4, LEE5 and espG operons at $27^{\circ} \mathrm{C}$ in wild-type EPEC. We transformed wild-type EPEC with a plasmid encoding ler expressed from the Ptac regulated promoter (pTU14). The transformed strain was grown at $27^{\circ} \mathrm{C}$ and the effect of ler expression on the production of intimin, Tir, EspA, EspB and EspF was tested by Western analysis. The results clearly show that supplying Ler in trans at $27^{\circ} \mathrm{C}$ is sufficient to activate the production of these proteins (Fig. 3A).

To further confirm these results, EPEC strains containing plasmids encoding $g f p$ transcriptional fusions with regulatory regions of $L E E 2, L E E 3, L E E 4, L E E 5$ or $\operatorname{esp} G$ (see Fig. 1) were transformed with a compatible plasmid encoding Ptac-ler (pTU14). We compared $g f p$ expression at $27^{\circ} \mathrm{C}$ in the absence or presence of Ler supplied in trans. Expression of all of the examined LEE operons in the absence of pTU14 was low, at background levels. In contrast, supplying Ler in trans from pTU14 resulted in increased expression of LEE2, LEE3, LEE4, LEE5 and espG by 12-, 7-, 15-, 13- and 7-fold, respectively (Fig. 3B). Expression of $g f p$ transcriptional fusions with tac or oxyS promoters was not affected by Ler (data not shown). These results indicate that expression of Ler is sufficient to induce the expression of LEE2, LEE3, LEE4, LEE5 and espG in wild-type EPEC encoding $h n s$ and grown at the non-permissive temperature of $27^{\circ} \mathrm{C}$.

\section{Expression of LEE genes in EPEC double mutant inactivated in both ler and $h n s$ genes}

To further substantiate the role of $\mathrm{H}-\mathrm{NS}$ in the regulation of LEE2, LEE3, LEE4, LEE5 and espG without any possible interference of Ler, we constructed an EPEC double mutant inactivated in both $h n s$ and ler. This EPEC mutant was constructed by using the Lambda Red recombinase system that enables recombination of linear DNA into the E. coli K-12 genome as described by Datsenko \& Wanner (2000) (see Methods). We compared the expression of LEE genes in the background of the following isogenic EPEC strains: wild-type, ler::kan, hns::kan and ler::kan hns::cat. The four strains were grown at $37^{\circ} \mathrm{C}$ and analysed by immunoblotting using antibodies raised against EspA, EspB (LEE4-encoded proteins), intimin and Tir (LEE5encoded proteins). The EPEC ler hns double mutant expressed EspA and EspB at levels comparable to the hns mutant. However, this mutant expressed Tir and intimin to levels significantly lower than the hns mutant (Fig. 4A). As expected, the EPEC hns mutant expressed these proteins at levels comparable to the wild-type EPEC, while the ler mutant did not express any of these proteins (Fig. 4A).

We transformed each of the four EPEC strains wild- 


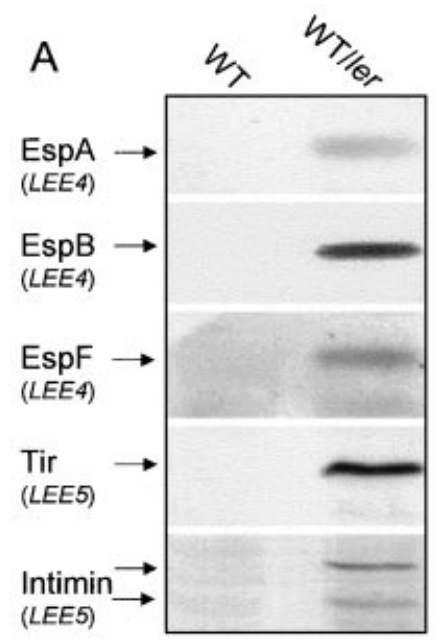

B

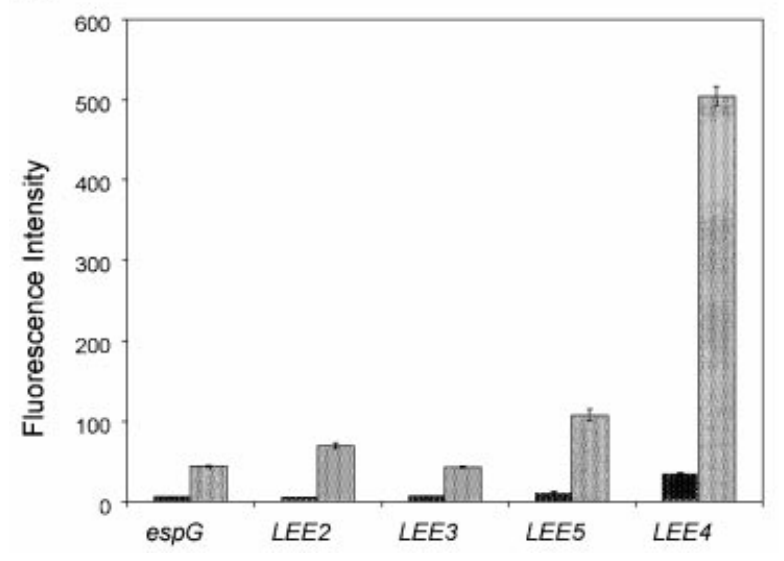

Fig. 3. Expression of ler in trans rescues the expression of LEE genes in EPEC grown at $27^{\circ} \mathrm{C}$. (A) Immunoblot analysis. Proteins were extracted from EPEC wild-type and EPEC/ler (bearing pTU14) grown at $27^{\circ} \mathrm{C}$. The extracted proteins were applied to SDS-PAGE followed by immunoblot analysis using anti-EspA, anti-EspB, anti-EspF, anti-Tir and anti-Intimin antibodies. (B) EPEC wild-type (black columns) and EPEC/ler (grey columns) bearing gfp fusions of espG, LEE2, LEE3, LEE4 and LEE5 were grown at $27^{\circ} \mathrm{C}$ and the fluorescence intensity was measured by flow cytometry. The values are the mean of three experiments and the standard error values are shown by error bars.

type, ler::kan, hns::kan and ler::kan hns::cat with plasmids containing the $g f p$ transcriptional fusions with the regulatory regions of LEE1, LEE2, LEE3, LEE4, $L E E 5$ or espG (see Fig. 1). The bacteria were grown at $37^{\circ} \mathrm{C}$ and the level of $g f p$ expression was compared (Fig. 4B). Expression of all the LEE operons in the hns: kan background was similar to that exhibited by the wildtype EPEC, or somewhat higher, while expression in the ler::kan background was strongly inhibited, except for LEE1 (Fig. 4B). In contrast to ler::kan, in the background of ler: : kan hns:: cat, expression of LEE2, LEE3, LEE4 and espG was completely restored, while expression of LEE5 was only partially restored (Fig. 4B). As expected, a control using LEE1 fusion exhibited a similar GFP level in the different background strains.
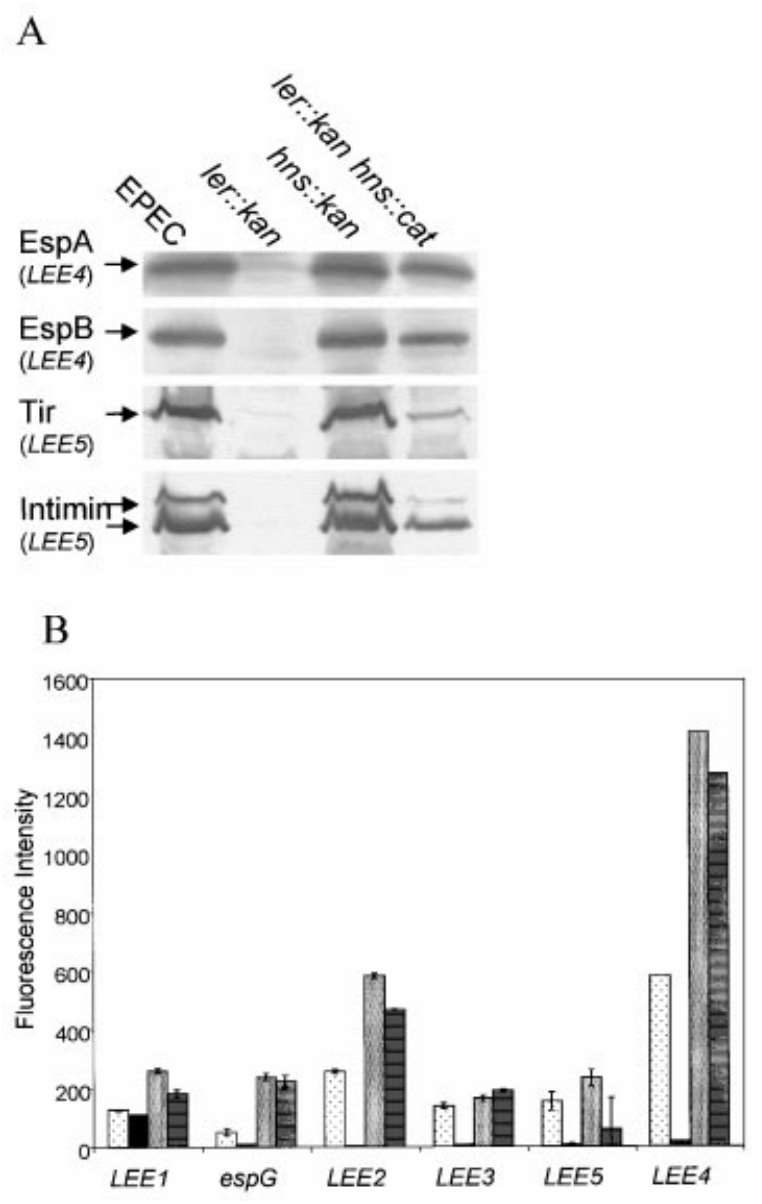

Fig. 4. Expression of LEE genes in EPEC double mutant inactivated in both $h n s$ and ler genes. (A) Immunoblot analysis. Protein extracts were prepared from EPEC wild-type, ler::kan, hns::kan, and ler::kan hns::cat mutants, grown at $37^{\circ} \mathrm{C}$. The extracted proteins were applied to SDS-PAGE followed by immunoblot analysis using anti-EspA, anti-EspB, anti-Tir and anti-Intimin antibodies. (B) Flow cytometry. EPEC wild-type (dotted columns), ler::kan (black columns), hns::kan (light grey columns) and ler::kan hns::cat (dark grey columns) mutants bearing gfp transcriptional fusions of $L E E 1$, espG, LEE2, LEE3, $L E E 5$ and $L E E 4$ were grown at $37^{\circ} \mathrm{C}$. The expression levels were determined by flow cytometry. The values are the mean of three experiments and the standard error values are shown by error bars.

Taken together, the results shown in Fig. 4 indicate that in the absence of H-NS, Ler is dispensable for full expression of LEE2, LEE3, LEE4 and espG but it is still needed for efficient expression of LEE5. Furthermore, the derepression of LEE2, LEE3, LEE4, LEE5 and espG in the hns ler double mutant, in contrast to the repression in the ler mutant, suggests that H-NS mediates the repression of each of these transcriptional units.

\section{H-NS binds to the LEE1 and LEE2-LEE3 promoter regions}

We tested whether regulation by $\mathrm{H}-\mathrm{NS}$ involves its interaction with the regulatory regions of LEE1 and LEE2-LEE3. H-NS was purified as described by Dersch 

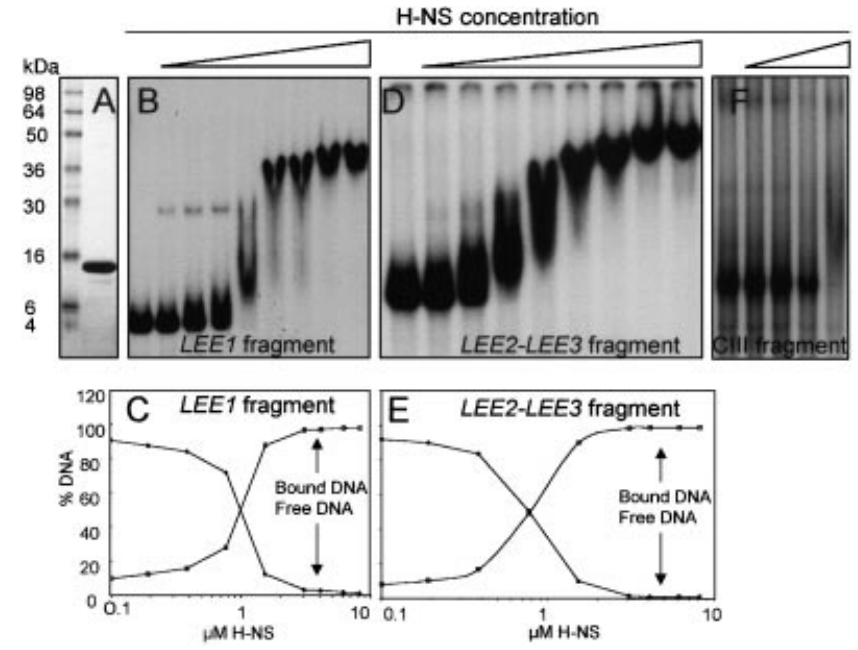

Fig. 5. H-NS binds to the promoter region of $L E E 1$ and to the overlapping promoter region of LEE2 and LEE3. (A) Purified $\mathrm{H}-$ NS protein was subjected to SDS-PAGE followed by Coomassie blue staining. (B) A gel shift assay of the LEE1 promoter region with H-NS. A DNA fragment corresponding to the sequence from position -173 to +11 relative to the LEE1 transcriptional start point (LEE1 fragment) was mixed with increasing concentrations $(0,0.191,0.382,0.765,1.531,3.062,4.080,6.125$ and $8.160 \mu \mathrm{M}$ ) of H-NS. (C) Quantification of the gel-shift results with the $L E E 1$ fragment using a phosphorimager. (D) $A$ gel shift assay of $L E E 2$ and $L E E 3$ regulatory region with $\mathrm{H}-\mathrm{NS}$. A DNA fragment, corresponding to position +117 to -288 relative to $L E E 2$ transcriptional start point (LEE2-LEE3 fragment) was mixed with increasing concentrations $(0,0.191,0.382$, $0.765,1.531,3.062,4.080,6.125$ and $8.160 \mu \mathrm{M}$ ) of H-NS. (E) Quantification of the gel-shift results with the LEE2-LEE3 fragment using a phosphorimager. (F) A gel shift assay of a $\lambda$ CIII DNA fragment with H-NS. A $171 \mathrm{bp}$ DNA fragment containing the CIII coding region was incubated with increasing concentrations $(0,1.020,2.040,4.080$ and $8.160 \mu \mathrm{M})$ of H-NS.

et al. (1993) (Fig. 5A) and used in gel shift assays with three DNA fragments: a fragment that extends nucleotides -173 to +11 relative to $L E E 1$ transcriptional start site (LEE1 fragment), a fragment containing the overlapping promoter region and the flanking $5^{\prime}$ coding regions of $L E E 2$ and $L E E 3$, corresponding to nucleotide positions +117 to -288 relative to $L E E 2$ transcriptional start point (LEE2-LEE3 fragment), and a control fragment driven from the CIII gene of Lambda phage. The LEE1 and LEE2-LEE3 fragments formed lowmobility complexes in the presence of H-NS (Fig. 5B, D). However, the formation of a low-mobility complex with the control CIII DNA fragment was insignificant and demanded a much higher H-NS concentration (Fig. 5F). This indicates a preferential binding of H-NS to the LEE1 and LEE2-LEE3 fragments. To assess the apparent binding affinity, we performed a quantitative analysis of the free and bound DNA in the presence of increasing (1.5 to 2 -fold) H-NS concentrations (Fig. 5C, E). A small increase (about 1.5 to 2 -fold) in H-NS concentration was sufficient to shift the majority of the LEE1 DNA, as well as the LEE2-LEE3 DNA, from a free to a protein-bound form, suggesting a cooperative binding mode of H-NS. The data show an apparent dissociation constant $(\mathrm{Kd}$, protein concentration that binds $50 \%$ of the DNA) of $0.95 \mu \mathrm{M}$ and $0.80 \mu \mathrm{M}$ with LEE1 and LEE2-LEE3 fragments respectively. In both cases the curve shape confirms a cooperative binding mode of H-NS. The binding of H-NS to the LEE promoter regions is consistent with its role as a repressor of each of these LEE genes.

\section{DISCUSSION}

In this study we show a regulatory cascade of the thermoregulation of LEE genes encoding the type III secretion system and effector proteins in EPEC. The expression of ler, a LEE1 gene that encodes a positive regulator of most other LEE genes, is subjected to temperature-dependent regulation mediated by H-NS: it is repressed at $27^{\circ} \mathrm{C}$ but not at $37^{\circ} \mathrm{C}$. In contrast, all other major LEE operons are repressed by H-NS both at $27^{\circ} \mathrm{C}$ and $37^{\circ} \mathrm{C}$. We used two independent techniques to compare wild-type EPEC and the EPEC hns::kan mutant: Western analysis and $g f p$ transcriptional $\mathrm{fu}-$ sions. Analysis of $g f p$ transcriptional fusions carried by a low to medium copy-number plasmid was recently further approved as an accurate and reliable system for monitoring transcriptional regulation in E. coli (Kalir et al., 2001). We show that at the non-permissive temperature of $27^{\circ} \mathrm{C}$, H-NS represses the expression of LEE1, LEE2, LEE3, LEE4, LEE5 and espG. In contrast, at $37^{\circ} \mathrm{C}$ the differences in expression levels between the wild-type and the hns mutant were relatively small. By supplying Ler in trans we demonstrated that ectopic expression of ler at $27^{\circ} \mathrm{C}$ is sufficient to activate the expression of LEE2, LEE3, LEE4, LEE5 and espG by EPEC wild-type. Taken together, it is evident that $\mathrm{H}$-NS strongly represses LEE1 at $27^{\circ} \mathrm{C}$, but at $37^{\circ} \mathrm{C}$ this repression is inefficient (see Table 3 ).

However, it was more complicated to draw conclusions regarding the role of $\mathrm{H}-\mathrm{NS}$ in the regulation of all other LEE operons, since the LEE1-encoded Ler is a positive regulator of these operons. Therefore, to examine the role of H-NS without the interference of Ler, we constructed an EPEC strain mutated in both hns and ler. The analysis of LEE gene expression in this double mutant was particularly informative. While in the absence of Ler at $37^{\circ} \mathrm{C}$ the expression of LEE2, LEE3, LEE4, LEE5 and espG operons was repressed, the repression was alleviated upon further inactivation of hns. These results indicate that H-NS represses each of these operons regardless of Ler. While at $37^{\circ} \mathrm{C}$ the $\mathrm{H}$ NS-mediated repression of LEE1 was inefficient, H-NS efficiently repressed the other operons at $37{ }^{\circ} \mathrm{C}$, including LEE2, LEE3, LEE4, LEE5 and espG.

We further showed that in the absence of H-NS, Ler was dispensable for full expression of LEE2, LEE3, LEE4 and espG. This suggests that Ler activates expression of these operons exclusively by preventing the H-NSmediated repression. However, inactivation of hns was insufficient for a complete restoration of LEE5 expression, in the absence of Ler, suggesting that Ler activates expression of LEE5 both by antagonizing the 

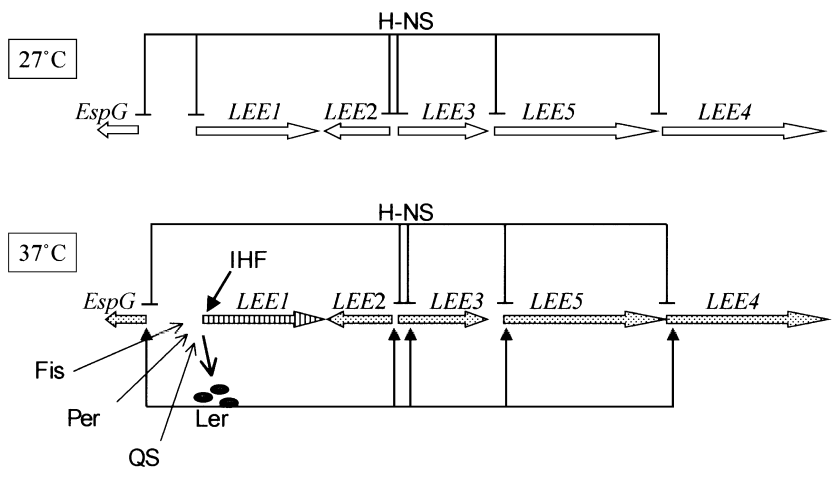

Fig. 6. A schematic model of the regulatory network of LEE gene expression. At $27^{\circ} \mathrm{C}$, $\mathrm{H}$-NS mediates the repression of all major LEE operons (upper panel). Upon shifting the temperature from $27^{\circ} \mathrm{C}$ to $37^{\circ} \mathrm{C}$ (lower panel), the expression of LEE2, LEE3, LEE4, LEE5 and espG is still repressed by $\mathrm{H}-\mathrm{NS}$, while the expression of LEE1, that is activated by IHF and modulated by Fis, Per and quorum sensing (QS), is alleviated. This leads to the production of Ler, which subsequently activates the expression of $L E E 2, L E E 3, L E E 4, L E E 5$ and espG. Ler mediates the activation of these transcriptional units by alleviating the H-NS-mediated repression. The horizontal arrows represent LEE transcriptional units, their heads point in the direction of transcription; white horizontal arrows indicate repressed genes. The striped horizontal arrow represents the temperature-mediated $37{ }^{\circ} \mathrm{C}$-expressed LEE1 operon; dotted horizontal arrows represent Ler-activated LEE operons. The vertical arrows represent positive regulation of LEE genes; the inverted Ts represent negative regulation of LEE genes.

H-NS mediated repression as well as by an additional mechanism, as yet to be defined.

Based on these results, our current working model, presented in Fig. 6, is as follows. At the non-permissive temperature of $27^{\circ} \mathrm{C}, \mathrm{H}-\mathrm{NS}$ mediates repression of LEE1, LEE2, LEE3, LEE4, LEE5 and espG. The physical evidence that H-NS binds to the LEE1 and LEE2-LEE3 regulatory regions supports the speculation that $\mathrm{H}-\mathrm{NS}$ might act as a direct repressor of these operons. It is yet to be confirmed that this interaction occurs also in the case of the other LEE operons. According to our model, upon shifting the temperature from $27^{\circ} \mathrm{C}$ to $37^{\circ} \mathrm{C}$, the expression of $L E E 1$ is alleviated while the expression of LEE2, LEE3, LEE4, LEE5 and espG is still repressed by $\mathrm{H}$-NS. The production of Ler at $37^{\circ} \mathrm{C}$ subsequently activates the expression of LEE2, LEE3, LEE4, LEE5 and esp G. Ler mediates the activation of LEE2, LEE3, LEE4 and esp $G$ by alleviating the H-NS-mediated repression. Activation of LEE5 by Ler involves both antagonizing the H-NS repression and an additional, as yet unknown mechanism, that is independent of H-NS.

The preferential binding of H-NS to the LEE1 and LEE2-LEE3 promoter regions supports the genetic data that H-NS either alone or together with other factors represses these operons. In the case of the LEE2-LEE3, the H-NS binding region overlaps with the Ler-binding region (Sperandio et al., 2000). The pattern of H-NS binding to the tested DNA fragments indicates that multiple copies of H-NS bind to the LEE1 and LEE2$L E E 3$ promoter regions in a cooperative way, typical to
H-NS binding in other systems (Atlung \& Ingmer, 1997).

In conclusion, our results on the opposite role of Ler and HNS in respect to expression of the LEE2 and LEE3 operon confirm and substantiate a previous report (Bustamante et al., 2001). In addition we show, for the first time, the opposite role of these two regulators in the case of three additional LEE operons, namely the LEE4, LEE5 and $\operatorname{esp}$ G. More importantly, we describe here for the first time the role of H-NS in temperature-dependent repression of the LEE1 operon including ler. This repression is the basis for the thermoregulated expression of all other LEE operons.

In enteroinvasive E. coli and Shigella, virulence genes are repressed at $30{ }^{\circ} \mathrm{C}$ and expressed at $37^{\circ} \mathrm{C}$ (Maurelli \& Sansonetti, 1988). H-NS is involved in the thermoregulation of virF (Falconi et al., 1998), the first positive activator of a multi-step regulatory cascade leading to expression of the type III secretion system and other virulence effectors (Dorman \& Porter, 1998). It was proposed that the physical basis for the thermoregulated expression of $v i r F$ resides in a temperature-dependent structural modification of the virF promoter, resulting from a temperature-sensitive curved DNA structure (Falconi et al., 1998). H-NS also mediates repression of the virB gene downstream in the Shigella regulatory cascade (Tobe et al., 1993). The regulatory cascade in EPEC, whereby the expression of Ler is thermoregulated by H-NS, is apparently analogous to the Shigella system. However, in EPEC the role of H-NS is more complex, given its involvement in repression of all other major LEE operons, and because of the activity of Ler as a positive regulator that prevents H-NS-mediated repression of all other LEE operons.

We hypothesize that a temperature-dependent DNAtopology modification of the LEE1 promoter region might play a role in the thermoregulation of LEE1. This hypothesis is supported by our previous data showing that binding of IHF upstream of the LEE1 promoter is essential for LEE1 expression (Friedberg et al., 1999). IHF that binds to DNA in specific sites bends the DNA to form nucleoprotein complexes (Rice et al., 1996). The IHF-dependent modification of the DNA curvature might change the accessibility to H-NS in a temperaturedependent manner. It remains to be seen if IHF antagonizes $\mathrm{H}-\mathrm{NS}$ and thereby alleviates the H-NS mediated repression of LEE1 at $37^{\circ} \mathrm{C}$. In DNase footprinting experiments $\mathrm{H}-\mathrm{NS}$ does not show any distinct footprinting, but protects extended DNA sequences of the LEE1 promoter region, including the IHF binding site (not shown). Interplays, either synergistic or antagonistic, between histone-like proteins, including $\mathrm{H}-\mathrm{NS}$ and IHF, have been implicated in several unrelated genetic systems (McLeod \& Johnson, 2001). For instance, in the case of the early promoter of bacteriophage $\mathrm{Mu}$, it was shown that IHF interacts directly with the transcription initiation complex and in addition alleviates the H-NS mediated repression of the Pe promoter (van Ulsen et al., 1996). In the case of Shigella flexneri 
virulence genes it was reported that IHF mediates virB expression by overcoming the repression exerted by $\mathrm{H}-$ NS (Porter \& Dorman, 1997).

A finely tuned regulation of the ler gene is presumably critical for the timing of LEE gene expression during infection. Fis, PerABC and quorum sensing are also involved in the regulation of LEE1 (Goldberg et al., 2001; Mellies et al., 1999; Sperandio et al., 1999). The future challenge is to define in EPEC and related organisms the role of all the various regulators and to characterize the interplay that mediates LEE gene expression in response to the host-environmental signals.

\section{ACKNOWLEDGEMENTS}

We thank E. Bremer and H. P. Dersch for the pPD3 plasmid and useful information, B. Wanner for the Lambda Red strains and G. Frankel for antibodies. This research was supported by the European Union Fifth Framework Quality of Life Program (grant QLK2-2000-00600), and by grants from the Israel-United States Binational Foundation, the Israeli Ministry for Science and the Israeli Ministry for Health. T.U. is supported by the Boehringer Ingelheim Scholarship for PhD students.

\section{REFERENCES}

Atlung, T. \& Ingmer, H. (1997). H-NS: a modulator of environmentally regulated gene expression. Mol Microbiol 24, 7-17.

Bustamante, V. H., Santana, F. J., Calva, E. \& Puente, J. L. (2001). Transcriptional regulation of type III secretion genes in enteropathogenic Escherichia coli: Ler antagonizes H-NS-dependent repression. Mol Microbiol 39, 664-678.

Cormack, B. P., Valdivia, R. H. \& Falkow, S. (1996). FACSoptimized mutants of the green fluorescent protein (GFP). Gene 173, 33-38.

Datsenko, K. A. \& Wanner, B. L. (2000). One-step inactivation of chromosomal genes in Escherichia coli K-12 using PCR products. Proc Natl Acad Sci US A 97, 6640-6645.

Dersch, P., Schmidt, K. \& Bremer, E. (1993). Synthesis of the Escherichia coli $\mathrm{K}-12$ nucleoid-associated DNA-binding protein $\mathrm{H}-\mathrm{NS}$ is subjected to growth-phase control and autoregulation. Mol Microbiol 8, 875-889.

Dersch, P., Fsihi, H. \& Bremer, E. (1994). Low-copy-number T7 vectors for selective gene expression and efficient protein overproduction in Escherichia coli. FEMS Microbiol Lett 123, 19-26.

Donnenberg, M. S. \& Kaper, J. B. (1991). Construction of an eae deletion mutant of enteropathogenic Escherichia coli by using a positive-selection suicide vector. Infect Immun 59, 4310-4317.

Dorman, C. J. \& Porter, M. E. (1998). The Shigella virulence gene regulatory cascade: a paradigm of bacterial gene control mechanisms. Mol Microbiol 29, 677-684.

Elliott, S. J., Wainwright, L. A., McDaniel, T. K., Jarvis, K. G., Deng, Y. K., Lai, L. C., McNamara, B. P., Donnenberg, M. S. \& Kaper, J. B. (1998). The complete sequence of the locus of enterocyte effacement (LEE) from enteropathogenic Escherichia coli E2348/69. Mol Microbiol 28, 1-4.

Elliott, S. J., Hutcheson, S. W., Dubois, M. S., Mellies, J. L., Wainwright, L. A., Batchelor, M., Frankel, G., Knutton, S. \& Kaper, J. B. (1999). Identification of CesT, a chaperone for the type III secretion of Tir in enteropathogenic Escherichia coli. Mol Microbiol 33, 1176-1189.

Falconi, M., Colonna, B., Prosseda, G., Micheli, G. \& Gualerzi, C. O. (1998). Thermoregulation of Shigella and Escherichia coli EIEC pathogenicity: a temperature-dependent structural transition of DNA modulates accessibility of virF promoter to transcriptional repressor H-NS. EMBO J 17, 7033-7043.

Forsman, K., Sonden, B., Goransson, M. \& Uhlin, B. E. (1992). Antirepression function in Escherichia coli for the cAMP-cAMP receptor protein transcriptional activator. Proc Natl Acad Sci US A 89, 9880-9884.

Frankel, G., Phillips, A. D., Rosenshine, I., Dougan, G., Kaper, J. B. \& Knutton, S. (1998). Enteropathogenic and enterohaemorrhagic Escherichia coli: more subversive elements. Mol Microbiol 30, 911-921.

Friedberg, D., Umanski, T., Fang, Y. \& Rosenshine, I. (1999). Hierarchy in the expression of the locus of enterocyte effacement genes of enteropathogenic Escherichia coli. Mol Microbiol 34, 941-952.

Goldberg, M. D., Johnson, M., Hinton, J. C. \& Williams, P. H. (2001). Role of the nucleoid-associated protein Fis in the regulation of virulence properties of enteropathogenic Escherichia coli. Mol Microbiol 41, 549-559.

Hommais, F., Krin, E., Laurent-Winter, C., Soutourina, O., Malpertuy, A., Le Caer, J. P., Danchin, A. \& Bertin, P. (2001). Large-scale monitoring of pleiotropic regulation of gene expression by the prokaryotic nucleoid-associated protein, H-NS. Mol Microbiol 40, 20-36.

Jordi, B. J., Dagberg, B., de Haan, L. A., Hamers, A. M., van der Zeijst, B. A., Gaastra, W. \& Uhlin, B. E. (1992). The positive regulator $\mathrm{CfaD}$ overcomes the repression mediated by histonelike protein $\mathrm{H}-\mathrm{NS}(\mathrm{H} 1)$ in the CFA/I fimbrial operon of Escherichia coli. EMBO J 11, 2627-2632.

Kalir, S., McClure, J., Pabbaraju, K., Southward, C., Ronen, M., Leibler, S., Surette, M. G. \& Alon, U. (2001). Ordering genes in a flagella pathway by analysis of expression kinetics from living bacteria. Science 292, 2080-2083.

Kanamaru, K., Tatsuno, I., Tobe, T. \& Sasakawa, C. (2000). SdiA, an Escherichia coli homologue of quorum-sensing regulators, controls the expression of virulence factors in enterohaemorrhagic Escherichia coli O157:H7. Mol Microbiol 38, 805-816.

Knutton, S., Rosenshine, I., Pallen, M. J., Nisan, I., Neves, B. C., Bain, C., Wolff, C., Dougan, G. \& Frankel, G. (1998). A novel EspAassociated surface organelle of enteropathogenic Escherichia coli involved in protein translocation into epithelial cells. EMBO J 17, 2166-2176.

Maurelli, A. T. \& Sansonetti, P. J. (1988). Identification of a chromosomal gene controlling temperature-regulated expression of Shigella virulence. Proc Natl Acad Sci U S A 85, 2820-2824.

McDaniel, T. K. \& Kaper, J. B. (1997). A cloned pathogenicity island from enteropathogenic Escherichia coli confers the attaching and effacing phenotype on E. coli K-12. Mol Microbiol 23, 399-407.

McLeod, S. M. \& Johnson, R. C. (2001). Control of transcription by nucleoid proteins. Curr Opin Microbiol 4, 152-159.

Mellies, J. L., Elliott, S. J., Sperandio, V., Donnenberg, M. S. \& Kaper, J. B. (1999). The Per regulon of enteropathogenic Escherichia coli: identification of a regulatory cascade and a novel transcriptional activator, the locus of enterocyte effacement (LEE)-encoded regulator (Ler). Mol Microbiol 33, 296-306. 
Porter, M. E. \& Dorman, C. J. (1997). Positive regulation of Shigella flexneri virulence genes by Integration Host Factor. J Bacteriol 179, 6537-6550.

Rice, P. A., Yang, S., Mizuuchi, K. \& Nash, H. A. (1996). Crystal structure of an IHF-DNA complex: a protein-induced DNA Uturn. Cell 87, 1295-1306.

Rosenshine, I., Ruschkowski, S. \& Finlay, B. B. (1996). Expression of attaching/effacing activity by enteropathogenic Escherichia coli depends on growth phase, temperature, and protein synthesis upon contact with epithelial cells. Infect Immun 64, 966-973.

Sanchez-SanMartin, C., Bustamante, V. H., Calva, E. \& Puente, J. L. (2001). Transcriptional regulation of the orf19 gene and the tir-cesT-eae operon of enteropathogenic Escherichia coli. J Bacteriol 183, 2823-2833.

Sperandio, V., Mellies, J. L., Nguyen, W., Shin, S. \& Kaper, J. B. (1999). Quorum sensing controls expression of the type III secretion gene transcription and protein secretion in enterohemorrhagic and enteropathogenic Escherichia coli. Proc Natl Acad Sci U S A 96, 15196-15201.

Sperandio, V., Mellies, J. L., Delahay, R. M., Frankel, G., Crawford,
J. A., Nguyen, W. \& Kaper, J. B. (2000). Activation of enteropathogenic Escherichia coli (EPEC) LEE2 and LEE3 operons by Ler. Mol Microbiol 38, 781-793.

Studier, F. W. \& Moffatt, B. A. (1986). Use of bacteriophage T7 RNA polymerase to direct selective high-level expression of cloned genes. J Mol Biol 189, 113-130.

Tobe, T., Yoshikawa, M., Mizuno, T. \& Sasakawa, C. (1993). Transcriptional control of the invasion regulatory gene $\operatorname{vir} B$ of Shigella flexneri: activation by VirF and repression by H-NS. J Bacteriol 175, 6142-6149.

van Ulsen, P., Hillebrand, M., Zulianello, L., van de Putte, P. \& Goosen, N. (1996). Integration host factor alleviates the H-NSmediated repression of the early promoter of bacteriophage $\mathrm{Mu}$. Mol Microbiol 21, 567-578.

Wolff, C., Nisan, I., Hanski, E., Frankel, G. \& Rosenshine, I. (1998). Protein translocation into host epithelial cells by infecting enteropathogenic Escherichia coli. Mol Microbiol 28, 143-155.

Received 21 March 2002; revised 7 May 2002; accepted 21 May 2002. 